\title{
Ecologia e história natural de uma taxocenose de serpentes no Núcleo Santa Virgínia do Parque Estadual da Serra do Mar, no sudeste do Brasil
}

\author{
Paulo Afonso Hartmann ${ }^{1,3}$, Marília Teresinha Hartmann ${ }^{1}$ \& Marcio Martins ${ }^{2}$ \\ ${ }^{1}$ Universidade Federal do Pampa, Campus São Gabriel, \\ Av. Antônio Trilha, $n^{\circ} 1847$, 97300-000, São Gabriel, RS, Brasil. \\ ${ }^{2}$ Departamento de Ecologia, Instituto de Biociências, Universidade de São Paulo, \\ Rua do Matão, Trav. 14, $n^{\circ}$ 101, 05508-090, São Paulo, São Paulo, Brasil. \\ ${ }^{3}$ Autor para correspondência: Paulo Afonso Hartmann, e-mail: hartmann.paulo@gmail.com
}

HARTMANN, P.A., HARTMANN, M.T. \& MARTINS, M. Ecology and natural history of a snake assemblage at Núcleo Santa Virgínia, Parque Estadual da Serra do Mar, southeastern Brazil. Biota Neotrop., 9(3): http:// www.biotaneotropica.org.br/v9n3/en/abstract?article+bn03609032009.

\begin{abstract}
The objective of this study was to describe the natural history and the ecology of a snake assemblage in the Atlantic rainforest, at Núcleo Santa Virgínia, Parque Estadual da Serra do Mar, located on the northeastem of the state of São Paulo, southeastern Brazil. We describe richness, relative abundance, daily and seasonal activity, and substrate use, besides additional aspects of the natural history of the snakes. A total of 148 individuals, of 27 species, 19 genera and four families, were found within the area of the Núcleo Santa Virgínia. Species that were sampled more frequently were Bothrops jararaca, Xenodon neuwiedii and Liophis atraventer. Among the abiotic factors analyzed, minimum temperature, followed by mean temperature and rainfall are apparently the most important in determining snake abundance and/or activity. Most species presented a diet concentrated on one prey category or restricted to a few major food items. Frogs seem to be the most important food resource for snake assemblages in the Atlantic rainforest on the top of Serra do Mar. Our results indicate that the structure of the Núcleo Santa Virgínia snake assemblage reflects mainly the ecological characteristics of each of the lineages that compose the assemblage.
\end{abstract}

Keywords: diet, habitat use, activity, assemblage, snake.

HARTMANN, P.A., HARTMANN, M.T. \& MARTINS, M. Ecologia e história natural de uma taxocenose de serpentes no Núcleo Santa Virgínia do Parque Estadual da Serra do Mar, no sudeste do Brasil. Biota Neotrop., 9(3): http://www.biotaneotropica.org.br/v9n3/pt/abstract?article+bn03609032009.

Resumo: O objetivo deste estudo foi obter informações sobre a história natural e a ecologia de uma taxocenose de serpentes na Mata Atlântica do alto da Serra do Mar, no Núcleo Santa Virgínia do Parque Estadual da Serra do Mar, nordeste do Estado de São Paulo, Brasil. Os principais aspectos estudados foram riqueza, abundância relativa, padrões de atividade diária e sazonal, utilização do ambiente e dieta. Também são fornecidas informações adicionais sobre outros aspectos da história natural das espécies. Um total de 148 indivíduos, de 27 espécies, 19 gêneros e quatro famílias foi encontrado dentro dos limites do Núcleo Santa Virgínia. As espécies mais frequentemente encontradas foram Bothrops jararaca, Xenodon neuwiedii e Liophis atraventer. A maior parte das espécies é predominantemente diurna e terrícola. Dentre os fatores abióticos analisados para a área de estudo, o mais relacionado à abundância das serpentes foi a temperatura mínima, seguido da temperatura média e da pluviosidade. A maioria das espécies encontradas apresenta dieta concentrada em uma categoria de presa ou restrita a poucos tipos de itens alimentares. Aparentemente, anfíbios anuros são o principal recurso alimentar para as taxocenoses de serpentes da Mata Atlântica do alto da Serra do Mar. Os nossos resultados indicam que a estrutura da taxocenose de serpentes do Núcleo Santa Virgínia reflete principalmente as características ecológicas da linhagem mais representada na taxocenose.

Palavras-chave: dieta, uso do ambiente, atividade, taxocenose, serpente. 


\section{Introdução}

Por apresentarem conjuntos de espécies pertencentes a uma mesma linhagem e, portanto, com pelo menos parte da história evolutiva em comum, taxocenoses podem fornecer informações valiosas sobre as diferentes formas pelas quais distintas espécies respondem a fatores ecológicos (bióticos e abióticos; ver Cadle \& Greene 1993). Neste sentido, estudos com taxocenoses de vertebrados apresentam grande potencial para a compreensão dos fatores ecológicos e históricos envolvidos na formação das comunidades atuais. Taxocenoses de serpentes sul-americanas foram estudadas principalmente em áreas florestadas da Amazônia (Duellman 1978, Henderson et al. 1979, Dixon \& Soini 1986, Zimmerman \& Rodrigues 1990, Martins \& Oliveira 1999, Santos-Costa 2003, Bernarde 2004, Maschio 2008), mas também no Cerrado (Vanzolini 1948, França \& Araújo. 2006, Sawaya et al. 2008), Caatinga (Vitt \& Vangilder 1983), Pantanal (Strüssmann \& Sazima 1993), Floresta Atlântica (Marques 1998, Argôlo 2004) e regiões de Floresta com Araucária e Campos Sulinos (Cechin 1999, Di-Bernardo, 1998, Outeiral 2006, Zanella \& Cechin 2006, Balestrin 2008). Estudos sobre taxocenoses de serpentes são escassos para a Mata Atlântica de altitude. Como conseqüência, muitas características da vida das espécies de serpentes nesta região permanecem desconhecidas. No entanto, são estas informações sobre história natural, quando obtidas para o conjunto de espécies de uma localidade, que proporcionam subsídios para o entendimento da estrutura das taxocenoses. Este estudo teve como objetivo principal estimar a composição faunística e obter informações de história natural das espécies que compõem a taxocenose de serpentes no Núcleo Santa Virgínia, no alto da Serra do Mar, no Estado de São Paulo. Os dados serviram de subsídio para discutir os fatores relacionados à estrutura da taxocenose.

\section{Métodos}

\section{1. Área de estudo}

O estudo foi realizado no Núcleo Santa Virgínia do Parque Estadual da Serra do Mar (23 $22^{\prime}$ 'S e $45^{\circ} 07^{\prime}$ O), localizado em grande parte no município de São Luís do Paraitinga, no alto da Serra do Mar, com altitudes que variam de 870 a $1.160 \mathrm{~m}$. Ao norte o Núcleo Santa Virgínia faz divisa com o Núcleo Cunha que por sua vez faz divisa com o Parque Nacional da Serra da Bocaina, formando um importante corredor ecológico no alto da Serra do Mar. A vegetação está dentro dos domínios da floresta ombrófila densa montana, caracterizada por cerca de $60 \%$ de florestas primárias, sendo o restante formado por áreas de campo nativo, capoeira, floresta secundária e reflorestamento (Pinus spp. e Eucalyptus spp.). A área amostrada foi de aproximadamente 4.400 ha, entre altitudes de 800 e $1.100 \mathrm{~m}$ e engloba os seguintes tipos de ambiente: floresta ombrófila densa (Mata Atlântica), mata em regeneração e transição entre áreas alteradas e mata secundária. A floresta desta região é caracterizada por uma mata nebulosa, com porte menor que a Mata Atlântica do litoral e aspecto característico, devido à cobertura dos troncos de várias espécies por musgos e à grande quantidade de epífitas (Figura 1). O clima predominante é o tropical temperado com duas estações marcadas, uma quente e úmida e outra fria e seca (ou menos úmida). O total mensal de chuvas é em média maior que $100 \mathrm{~mm}$ na estação chuvosa (de outubro a março) e inferior a $30 \mathrm{~mm}$ na estação seca (abril a setembro) com pluviosidade média de $1.500 \mathrm{~mm}$ anuais (1990-2003). A precipitação pluviométrica total anual em 2003 foi de $1.032 \mathrm{~mm}$ e a maior precipitação ocorreu em janeiro $(286 \mathrm{~mm})$. $\mathrm{Na}$ época mais fria, entre os meses de junho e setembro, é comum a região ficar coberta por neblina, com períodos curtos do dia com céu

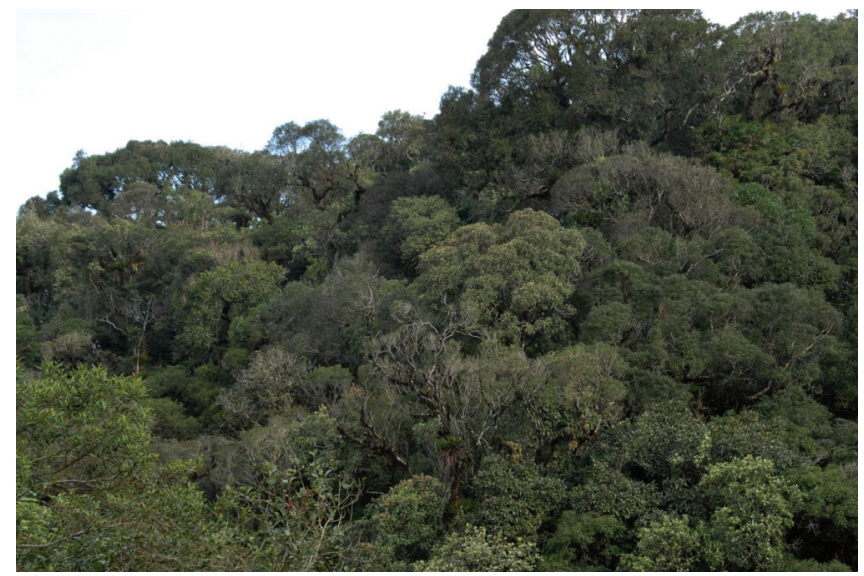

Figura 1. Mata Atlântica do alto da Serra do Mar no Núcleo Santa Virgínia do Parque Estadual da Serra do Mar, no estado de São Paulo, Brasil.

Figure 1. Atlantic Forest on the top of Serra do Mar, at Núcleo Santa Virgínia, Parque Estadual da Serra do Mar, State of São Paulo, Brazil.

aberto, principalmente no meio do dia. A média anual de temperatura foi de $20,8{ }^{\circ} \mathrm{C}$. Os dados climáticos foram obtidos no Instituto Nacional de Metereologia, a partir da estação metereológica do sétimo distrito de metereologia, na sede de Taubaté $\left(23^{\circ} 02^{\prime} \mathrm{S}\right.$ e $\left.45^{\circ} 33^{\prime} \mathrm{O}\right)$, distante cerca de $50 \mathrm{~km}$ da área de estudo.

\section{Coleta de dados.}

O estudo teve duração de 15 meses, de janeiro de 2003 a março de 2004. As amostragens tiveram duração de nove a 12 dias por mês, totalizando 140 dias de trabalho de campo. O trabalho de campo serviu para estimar a riqueza, a abundância relativa, a atividade diária e sazonal, o uso do ambiente e do substrato das serpentes. As serpentes encontradas foram fotografadas, capturadas, medidas e soltas ou mortas e fixadas. Para cada serpente foram registradas as seguintes informações: espécie, data e horário da observação, habitat e microhabitat, comprimento rostro-cloacal $(\mathrm{mm})$ e comprimento da cauda (mm), massa ( $\mathrm{g}$ ), sexo e atividade. Utilizamos as seguintes categorias em relação ao microhabitat das serpentes: fossorial, terrícola, arborícola e aquática (e.g. Duellman 1989) e definimos como semiarborícola as serpentes que utilizam tanto o chão quanto a vegetação para repousar e caçar. Cada serpente coletada foi dissecada por meio de incisão ventral ao longo dos dois terços posteriores do corpo (Martins \& Gordo 1993). Foram obtidas as seguintes informações: conteúdo do tubo digestivo, número de itens alimentares e condição reprodutiva. Uma espécie foi considerada de dieta especializada quando um tipo de presa representou $75 \%$ ou mais do total de presas registradas (Martins et al. 2001). O comprimento rostro-cloacal do menor macho maduro e da menor fêmea madura de cada espécie serviu para diferenciar indivíduos adultos de imaturos (Shine 1977, Marques 1996, Hartmann \& Marques 2005).

Para avaliar o padrão de atividade sazonal das serpentes foram isolados os fatores que podem interferir na abundância de serpentes em diferentes épocas do ano: diferença no esforço amostral; diferença sazonal no número de serpentes (principalmente em função do recrutamento); e diferença sazonal na atividade das serpentes (Henderson et al. 1987). Admitiu-se um esforço amostral semelhante em todos os meses e a abundância mensal foi analisada de duas formas: com todos os indivíduos e somente com indivíduos adultos. Em relação à abundância relativa as espécies foram classificadas como abundantes (representaram mais de $15 \%$ dos encontros), comuns (entre 5 e $15 \%$ dos encontros), de abundância intermediária (entre 1 e $4 \%$ dos encontros), e raras (menos de $1 \%$ dos encontros). Para a 
caracterização da dieta, do período de atividade e do uso do substrato também foram utilizadas informações complementares, obtidas em outros estudos sobre serpentes da Mata Atlântica (ver Sazima \& Haddad 1992, Marques \& Sazima 2004, Marques et al. 2004).

\section{Métodos de amostragem}

Os seguintes métodos foram utilizados para amostragens de serpentes no Núcleo Santa Virgínia, ao longo dos 15 meses de trabalho de campo.

Procura limitada por tempo. Foram percorridas trilhas nos diversos ambientes, a pé e em ritmo lento (cerca de 100-20 metros/hora), esquadrinhando visualmente o ambiente à procura de serpentes (e. g., Martins \& Oliveira, 1999). Os períodos de amostragens foram de duas a quatro horas. Foram realizadas de 50-60 horas/homem de procura por mês. No total, ao longo de 15 meses de amostragens foram realizadas 762 horas/homem de procura limitada por tempo.

Procura em estradas. Consistiu no deslocamento de carro, em velocidade lenta (cerca de $30-40 \mathrm{~km} / \mathrm{h}$.), por estradas da área de estudo à procura de serpentes. Foram percorridos diariamente os $18 \mathrm{~km}$ de rodovia que cortam o parque (Rodovia Oswaldo Cruz, SP 125), nos dois sentidos. Adicionalmente foram percorridas estradas de terra que dão acesso a vilarejos da região. Mensalmente, de janeiro de 2003 a março de 2004, foram percorridos entre 290 e $432 \mathrm{~km}$, totalizando ao longo dos 15 meses $4.970 \mathrm{~km}$.

Coletas por terceiros. Recipientes de $20 \mathrm{~L}$ contendo formol a $15 \%$, foram distribuídos aos moradores do entorno do parque, para que pudessem colocar serpentes mortas (Cechin 1999, Sawaya et al. 2008). Fichas foram distribuídas juntamente aos recipientes, onde os colaboradores registraram informações sobre as serpentes, como horário e local do encontro. Foram distribuídos seis recipientes em janeiro de 2001, que foram revisados mensalmente. O esforço de amostragem até março de 2003 foi de 90 recipientes-mês.

Encontros ocasionais. Foram considerados encontros ocasionais os exemplares encontrados durante atividades não previstas pelos outros métodos. Foram incluídos neste método os encontros de serpentes durante os deslocamentos de carro não considerados na procura em estradas.

\section{Comentários taxonômicos}

Os indivíduos de Atractus sp. encontrados neste estudo provavelmente representam uma espécie ainda não descrita. Os exemplares foram comparados com outras espécies de Atractus ocorrentes na Mata Atlântica (ver Marques et al. 2004) e se diferenciam principalmente pelo padrão dorsal negro. O gênero Thamnodynastes é composto atualmente por treze espécies, com pelo menos mais quatro espécies a serem descritas (ver Franco \& Ferreira 2002, Franco et al. 2003). Thamnodynastes cf. nattereri (Thamnodynastes sp. 1 em Franco \& Ferreira 2002) é muito semelhante a T. hypoconia, diferindo desta pela porção ventral da cabeça imaculada, a região posterior do corpo mais escura que a anterior, linhas longitudinais menos conspícuas e escamas dorsais fracamente quilhadas (Franco \& Ferreira 2002). Neste estudo, utilizamos o nome Thamnodynastes cf. nattereri para os indivíduos da Mata Atlântica com as características descritas acima, seguindo o padrão utilizado por Marques \& Sazima (2004). A taxonomia em nível de família e subfamília está de acordo com o proposto Zaher et al. (2009).

\section{Resultados e Discussão}

\section{Diversidade}

Encontramos 27 espécies de serpentes, de 19 gêneros e quatro famílias (Tabela 1). A estimativa do número de espécies pelo estimador
Tabela 1. Serpentes registradas no Núcleo Santa Virgínia do Parque Estadual da Serra do Mar, de janeiro de 2003 a março de 2004. Número de indivíduos (N) e porcentagem em relação ao número total de indivíduos (\%).

Table 1. Snakes recorded at Núcleo Santa Virgínia, Parque Estadual da Serra do Mar from January 2003 to March 2004. Number of individuals found (N) and percentage of the total number of individuals $(\%)$.

\begin{tabular}{|c|c|c|}
\hline Família/espécie & $\mathbf{N}$ & $(\%)$ \\
\hline \multicolumn{3}{|l|}{ COLUBRIDAE } \\
\hline Chironius bicarinatus (Wied, 1820) & 5 & 3,4 \\
\hline Chironius exoletus (Linnaeus, 1758) & 2 & 1,3 \\
\hline \multicolumn{3}{|l|}{ DIPSADIDADE } \\
\hline Atractus sp. & 5 & 3,4 \\
\hline Dipsas alternans (Fischer, 1885) & 1 & 0,7 \\
\hline Echinanthera melanostigma (Wagler,1824) & 5 & 3,4 \\
\hline Echinanthera undulata (Wied, 1824) & 5 & 3,4 \\
\hline Elapomorphus quinquelineatus (Raddi, 1820) & 1 & 0,7 \\
\hline Liophis aesculapii (Linnaeus, 1766) & 9 & 6,1 \\
\hline Liophis atraventer Dixon \& Thomas, 1985 & 11 & 7,4 \\
\hline Liophis miliaris (Linnaues, 1758) & 1 & 0,7 \\
\hline Mussurana montana Franco, Marques \& Puorto, 1997 & 3 & 2,0 \\
\hline Oxyrhopus clathratus Duméril, Bribon \& Duméril, 1854 & 4 & 2,7 \\
\hline Philodryas patagoniensis (Girard, 1857) & 4 & 2,7 \\
\hline Sibynomorphus neuwiedi (Ihering, 1911) & 2 & 1,3 \\
\hline Siphlophis pulcher (Raddi, 1820) & 1 & 0,7 \\
\hline Taeniophallus affinis (Günther, 1858) & 4 & 2,7 \\
\hline Taeniophallus persimilis (Cope, 1869) & 1 & 0,7 \\
\hline Thamnodynastes cf. nattereri Mikan, 1828 & 5 & 3,4 \\
\hline Thamnodynastes strigatus (Günther, 1858) & 1 & 0,7 \\
\hline Tropidodryas striaticeps (Cope, 1869) & 1 & 0,7 \\
\hline Uromacerina ricardinii (Peracca, 1897) & 1 & 0,7 \\
\hline Xenodon neuwiedii Günther, 1863 & 27 & 18,2 \\
\hline \multicolumn{3}{|l|}{ ELAPIDAE } \\
\hline Micrurus corallinus (Merren, 1820) & 1 & 0,7 \\
\hline Micrurus decoratus (Jan, 1858) & 2 & 1,3 \\
\hline \multicolumn{3}{|l|}{ VIPERIDAE } \\
\hline Bothrops jararaca (Wied, 1824) & 37 & 25,0 \\
\hline Bothrops jararacussu Lacerda, 1884 & 1 & 0,7 \\
\hline Crotalus durissus Linnaeus, 1758 & 8 & 5,4 \\
\hline Total & 148 & 100 \\
\hline
\end{tabular}

de riqueza Jacknife de primeira ordem, utilizando todos os métodos, indica uma riqueza entre 32 e 40 espécies $\left(\mathrm{N}_{(\mathrm{J} 1)}=36,33 \pm 4,02\right)$. Aparentemente, com mais tempo de amostragem, mais espécies seriam acrescidas à lista de espécies que compõem a taxocenose. As espécies mais encontradas foram Bothrops jararaca $(\mathrm{N}=36)$, Xenodon neuwiedii $(\mathrm{N}=26)$ e Liophis atraventer $(\mathrm{N}=11)$. Duas espécies foram classificadas como abundantes (mais de 11 indivíduos encontrados) e representaram mais de $40 \%$ das serpentes encontradas (Tabela 1). Para os métodos utilizados, três espécies foram comuns (8-11 indivíduos), 12 foram de abundância intermediária (2-5 indivíduos) e 10 espécies foram raras (um indivíduo apenas). Como em outras taxocenoses de serpentes brasileiras (ver Martins 1994, Marques 1998, Cechin 1999, Sawaya et al. 2008), a espécie mais abundante é um viperídeo. A riqueza de serpentes no Núcleo Santa Virgínia parece estar relacionada à heterogeneidade ambiental. Se conside- 
rarmos o seu entorno, podemos caracterizar parte da área do estudo como região ecotonal, constituída primariamente por Mata Atlântica de altitude com influência de formações vegetais do planalto, como Cerrado e Campos de Altitude. Indivíduos de Crotalus durissus, Philodryas patagoniensis e Thamnodynastes strigatus são exemplos de espécies que foram encontradas somente nas áreas de transição no Núcleo Santa Virgínia.

\section{História natural das espécies}

Os dados obtidos proporcionaram uma visão ampla sobre diversos atributos ecológicos das espécies. No entanto, para melhor caracterização da ecologia das espécies foram utilizadas também informações complementares, obtidas em outros estudos sobre serpentes da Mata Atlântica (ver principalmente Sazima \& Haddad 1992, Marques 1998, Marques \& Sazima 2004, Marques et al. 2004). São apresentadas informações sobre história natural das espécies, principalmente referentes a abundância, uso do ambiente, período de atividade e hábito alimentar.

\section{FAMÍLIA COLUBRIDAE}

\section{Chironius bicarinatus}

Espécie de abundância intermediária pelos métodos de amostragem utilizados e de hábito semi-arborícola (Sazima \& Haddad 1992, Dixon et al. 1993, Marques \& Sazima 2004), foi encontrada principalmente na borda da mata $(\mathrm{N}=5)$, no chão $(\mathrm{N}=3)$ e sobre a vegetação $(\mathrm{N}=2)$. Um indivíduo estava em deslocamento na borda de mata, sobre a vegetação (cerca de $2 \mathrm{~m}$ ) e outro subindo em árvore com ninho de ave. Foi encontrada nos meses mais quentes do ano $(\mathrm{N}=3)$, mas também em abril $(\mathrm{N}=2)$. Todos os indivíduos foram encontrados durante o dia e ativos $(\mathrm{N}=5)$. A dieta é composta principalmente de anuros (Sazima \& Haddad 1992; Carvalho-Silva \& Fernandes 1994, Marques \& Sazima 2004), e no tubo digestivo dos espécimes examinados foram encontrados dois anuros (Scinax sp. e Eleutherodactylus sp.).

\section{Chironius exoletus}

Espécie de abundância intermediária pelos métodos de amostragem utilizados e de hábito semi-arborícola (Dixon et al. 1993), foi encontrada na borda da mata $(\mathrm{N}=2)$. Um indivíduo foi encontrado deslocando-se por galhos finos, a cerca de $30 \mathrm{~cm}$ do solo e outro frouxamente enrodilhado na borda da mata, aparentemente assoalhando. Foi encontrada nos meses de setembro e fevereiro, ativa durante o dia. Não encontramos itens alimentares nos indivíduos examinados, no entanto a dieta de $C$. exoletus é composta principalmente de anuros (Sazima \& Haddad 1992, Dixon at al. 1993, Marques \& Sazima 2004).

\section{FAMÍLIA DIPSADIDAE}

\section{Atractus sp.}

Espécie de abundância intermediária pelos métodos de amostragem utilizados, foi encontrada somente na borda da mata $(\mathrm{N}=5)$. Os indivíduos foram encontrados no chão, atropelados entre áreas de mata $(\mathrm{N}=4)$, ou atravessando a estrada $(\mathrm{N}=1)$. O hábito é fossóreo (Peters \& Orejas-Miranda 1970) e terrícola, como indicam os indivíduos encontrados sobre o solo. Provavelmente está restrita a áreas florestadas, podendo atravessar trechos curtos de área aberta. Foi encontrada somente nos meses mais quentes, de outubro a março $(\mathrm{N}=5)$. As espécies de Atractus normalmente são de hábitos noturnos ou noturnos e diurnos (Martins \& Oliveira 1993, 1999, Marques et al. 2004). Um indivíduo foi encontrado ativo durante o dia $(15: 30$ h) e outro recém atropelado no final da tarde (17:00 h). Outros dois indivíduos foram encontrados pela manhã e talvez tenham sido atropelados no período noturno. Assim, Atractus sp. parece ser tanto diurna como noturna. A dieta parece ser especializada em minhocas $(\mathrm{N}=2)$, como outras espécies do gênero (Martins \& Oliveira 1999). A captura das presas deve ocorrer sob o solo. Quando manuseada debateu-se e utilizou descarga cloacal $(\mathrm{N}=1)$.

\section{Dipsas alternans}

Espécie rara pelos métodos de amostragens utilizados, foi encontrada somente em áreas florestadas. De hábito arborícola, um único indivíduo foi encontrado deslocando-se sobre a vegetação (cerca 1,5 m do solo), durante a noite. Foi encontrada no mês de novembro. A atividade desta espécie parece ser noturna, assim como as demais espécies do gênero (Sazima 1989, Martins \& Oliveira 1999). A dieta das espécies de Dipsas é especializada em moluscos, que encontra deslocando-se sobre a vegetação durante a noite (Sazima 1989).

\section{Echinanthera melanostigma}

Espécie de abundância intermediária pelos métodos de amostragens utilizados, foi encontrada em áreas abertas $(\mathrm{N}=2)$, mata $(\mathrm{N}=1)$ e borda de mata $(\mathrm{N}=2)$. De hábito terrícola, foi encontrada deslocando-se no chão $(\mathrm{N}=5)$. Foi mais abundante nos meses do início $(\mathrm{N}=3)$ e final da estação mais chuvosa $(\mathrm{N}=2)$. A atividade é diurna e todos os indivíduos foram encontrados durante o dia e ativos. A dieta é composta de anuros (Marques et al. 2004 ). Nos indivíduos examinados foram encontrados Physalaemus olfersii e Hypsiboas leptolineatus. Estas duas espécies de anuros podem ser encontradas com frequiência no chão da mata $(P$. olfersii) ou na borda de charcos (H. leptolineatus, obs. pess.). O encontro desta espécie deslocando-se pelo chão e a presença destes itens alimentares indica que E. melanostigma forrageia ativamente no chão da mata e arredores.

\section{Echinanthera undulata}

Espécie de abundância intermediária pelos métodos de amostragens utilizados, foi encontrada em áreas abertas $(\mathrm{N}=2)$, mata $(\mathrm{N}=1)$ e borda de mata $(\mathrm{N}=2)$. De hábito terrícola, ocorreu sempre no chão $(\mathrm{N}=5)$. Foi encontrada principalmente nos meses quentes do ano $(\mathrm{N}=4)$. Indivíduos foram encontrados ativos durante o dia $(\mathrm{N}=4)$ e no crepúsculo vespertino $(\mathrm{N}=1)$, indicando atividade principalmente diurna. $\mathrm{O}$ indivíduo encontrado no período crepuscular estava deslocando-se próximo a charco, possivelmente forrageando. A dieta é composta por anuros (Marques et al. 2004). No tubo digestivo de um indivíduo foram encontrados restos de anuros.

\section{Elapomorphus quinquelineatus}

Espécie rara pelos métodos de amostragens utilizados, um indivíduo foi encontrado na borda da mata, deslocando-se pelo chão, em novembro $(\mathrm{N}=1)$. O hábito é criptozóico (Cardoso et al. 2001). A atividade desta espécie parece ser noturna, como indica o indivíduo encontrado ativo à noite $(21: 00 \mathrm{~h})$. A dieta é composta por vertebrados alongados e subterrâneos, como anfisbenas e possivelmente gimnofionas (Marques et al. 2004). No tubo digestivo do indivíduo examinado foram encontradas escamas de anfisbenas.

\section{Liophis aesculapii}

Espécie comum pelos métodos de amostragens utilizados, podendo ocorrer áreas abertas $(\mathrm{N}=6)$ e borda de mata $(\mathrm{N}=1)$. De hábito terrícola (Sazima \& Haddad 1992, Marques \& Puorto 1994), todos os indivíduos foram encontrados no chão $(\mathrm{N}=9)$. O grande número de indivíduos atropelados em estradas margeadas 
por diferentes formações vegetacionais $(\mathrm{N}=6)$ indica que esta espécie pode ocorrer em áreas alteradas e tem grande capacidade de deslocamento. Foi encontrada ativa principalmente nos meses de novembro e dezembro $(\mathrm{N}=5)$, época em que um casal foi encontrado atropelado à beira da estrada. Uma fêmea encontrada em dezembro apresentava ovos no oviduto $(\mathrm{N}=6$, comprimento do maior ovo $=42 \mathrm{~mm}$ ). A atividade é diurna (Duellman 1978, Sazima \& Haddad 1992, Marques \& Sazima 2004), podendo se estender até o crepúsculo $(\mathrm{N}=2)$. Ofiófaga, alimenta-se principalmente de colubrídeos terrícolas (Greene 1973, 1976, Sazima \& Abe 1991, Marques \& Puorto 1994). No tubo digestivo dos indivíduos examinados foram encontradas serpentes (Sibynomorphus neuwiedi e Mussurana montana) e escamas de outra serpente da família Colubridae. Ao contrário da maioria das serpentes ofiófagas, $L$. aesculapii ingere suas presas pela cauda ( $\mathrm{N}=2$; Greene 1976, Marques \& Puorto 1994). As duas espécies de serpentes ingeridas por $L$. aesculapii têm atividade noturna. A procura pela presa parece ser ativa, principalmente no chão, onde se desloca esquadrinhando o substrato. É provável que capture as presas em seus abrigos diurnos (Marques \& Puorto 1994), como indica sua atividade diurna e a captura de presas de hábitos noturnos.

\section{Liophis atraventer}

Espécie comum pelos métodos de amostragens utilizados, pode ocupar borda de mata $(\mathrm{N}=6)$, áreas florestadas $(\mathrm{N}=4)$ e área aberta $(\mathrm{N}=1)$. O hábito é terrícola, como indica o fato de todos os indivíduos terem sido encontrados no chão $(\mathrm{N}=11)$. Indivíduos de L. atraventer foram encontrados deslocando-se pelo chão da mata $(\mathrm{N}=3)$ e assoalhando na borda da mata $(\mathrm{N}=2)$. Um indivíduo foi encontrado recém morto dentro da mata, com marcas de predação por ave na parte anterior e dorsal do corpo. Essa espécie foi mais abundante nos meses de setembro a dezembro $(\mathrm{N}=9)$. Todos os indivíduos foram encontrados ativos e durante o dia, confirmando que esta espécie tem hábitos diurnos (Fernandes et al. 2003). A dieta é composta principalmente por anuros (Dixon \& Thomas 1985, Fernandes et al. 2003). Foram encontrados vestígios de anuros nos indivíduos examinados $(\mathrm{N}=4)$, sendo um identificado (Physalaemus sp.). Na área de estudo foram observados com frequência anuros deslocando-se no chão da mata ou próximo a charcos durante o dia, principalmente Physalaemus olfersii e P. cuvieri (obs. pess.). Liophis atraventer parece forragear no chão, esquadrinhando o ambiente à procura de presas sobre o solo ou na serapilheira.

\section{Liophis miliaris}

Espécie rara pelos métodos de amostragens utilizados, o único indivíduo encontrado estava deslocando-se em área alagada próximo a rio. Foi encontrada no mês de abril e o indivíduo coletado estava ativo no início da noite. A dieta é generalista, podendo capturar diferentes tipos de presas, como anuros, que parecem ser o item principal (Sazima \& Haddad 1992; Marques \& Sazima 2004), peixes (Marques \& Souza 1993), lagartos (Machado et al. 1998) e anfisbenas (Chicarino et al. 1998). No indivíduo examinado foi encontrado somente vestígios de anuros $(\mathrm{N}=1)$.

\section{Mussurana montana}

Espécie de abundância intermediária pelos métodos de amostragens utilizados, foi encontrada na borda da mata $(\mathrm{N}=2)$. De hábito terrícola, dois indivíduos foram encontrados mortos, onde havia ocorrido uma queimada. Um terceiro indivíduo de $M$. montana foi encontrado dentro do tubo digestivo de um espécime de Liophis aesculapii. Os espécimes queimados foram encontrados em junho e o apresado foi encontrado em novembro. A dieta é composta por serpentes e lagartos (Franco et al. 1997). No tubo digestivo do indivíduo de $M$. montana consumido por Liophis aesculapii, foi encontrado um lagarto (Pantodactylus sp.).

\section{Oxyrhopus clathratus}

Espécie de abundância intermediária pelos métodos de amostragens utilizados, ocorreu na borda da mata $(\mathrm{N}=3)$ e mata $(\mathrm{N}=1)$, sempre no chão $(\mathrm{N}=4)$. Um indivíduo foi encontrado deslocando-se pelo chão da mata, durante o dia e outro recématropelado em estrada margeada por mata, durante a noite. Os encontros ocorreram no início da estação quente $(\mathrm{N}=3)$. A atividade parece ser principalmente noturna, mas também pode ser encontrada ativa durante o dia $(\mathrm{N}=1)$. No tubo digestivo de um espécime foi encontrado um roedor.

\section{Philodryas patagoniensis}

Espécie de abundância intermediária pelos métodos de amostragens utilizados, foi encontrada principalmente em áreas abertas $(\mathrm{N}=3)$ e borda de mata $(\mathrm{N}=1)$. Espécie típica de áreas abertas (Sazima \& Haddad 1992, Hartmann \& Marques 2005), foi encontrada atropelada próximo a campo na borda do parque. De hábito principalmente terrícola, pode eventualmente subir na vegetação para forragear (Gonzaga et al. 1997, Hartmann 2001, Hartmann \& Marques 2005). Sua capacidade de deslocamento e os hábitos generalistas possivelmente permitem a invasão de áreas originalmente florestadas. A atividade é diurna $(\mathrm{N}=4)$ e nos horários mais quentes do dia (Sazima \& Haddad 1992, Hartmann \& Marques 2005). Philodryas patagoniensis tem dieta generalista e alimenta-se de anuros, lagartos, serpentes e aves (Sazima \& Hadadd 1992, Hartmann 2001, Lopez 2003, Hartmann \& Marques 2005). Procura suas presas ativamente, deslocando-se pelo chão e vegetação rasteira, esquadrinhando o ambiente e pode capturar presas ativas ou em seu local de repouso (Hartmann \& Marques 2005).

\section{Sibynomorphus neuwiedi}

Espécie de abundância intermediária pelos métodos de amostragens utilizados, foi encontrada dentro da mata $(\mathrm{N}=1)$ e na borda da mata $(\mathrm{N}=1)$. Um indivíduo foi encontrado forrageando sobre galhos finos durante a noite (cerca de $1 \mathrm{~m}$ ) e outro repousando entre troncos em um amontoado de lenha durante o dia. De hábito semi-arborícola, pode descer ao chão com frequiência (Oliveira 2001, Marques \& Sazima 2004). Foi encontrada nos meses de abril e outubro. A dieta é especializada em moluscos, principalmente lesmas (Oliveira 2001, Marques \& Sazima 2004). Nos indivíduos examinados não foram encontrados itens alimentares.

\section{Siphlophis pulcher}

Espécie rara pelos métodos de amostragens utilizados, o único indivíduo foi encontrado pela manhã, atropelado entre áreas de mata. Espécie semi-arborícola, pode descer ao solo para atravessar pequenas áreas abertas. Pode utilizar a vegetação para repousar durante o dia (Sazima \& Argolo 1994). Foi encontrada no mês de abril. A atividade é principalmente noturna, quando se desloca pelo chão ou na vegetação à procura de presas (Sazima \& Argolo 1994, Marques \& Sazima 2004). A dieta é composta de presas ectotérmicas (Sazima \& Argolo 1994, Prudente et al. 1998, Marques \& Sazima 2004). No tubo digestivo do indivíduo examinado foi encontrado um lagarto (Placosoma glabellum). 


\section{Taeniophallus affinis}

Espécie de abundância intermediária pelos métodos de amostragens utilizados, foi encontrada em área de mata $(\mathrm{N}=1)$ e em borda de mata $(\mathrm{N}=3)$. De hábito terrícola, foi encontrada deslocando-se pelo chão $(\mathrm{N}=3)$ e parada na borda da mata, aparentemente assoalhando $(\mathrm{N}=1)$. Foi encontrada somente nos meses mais quentes do ano, de outubro a março, pela manhã $(\mathrm{N}=4)$. Não encontramos itens alimentares nos exemplares examinados, no entanto Taeniophallus affinis alimenta-se principalmente de anuros (Barbo \& Marques 2003; Marques et al. 2004).

\section{Taeniophallus persimilis}

Espécie rara $(\mathrm{N}=1)$ pelos métodos de amostragens utilizados. Aparentemente terrícola, foi encontrada deslocando-se na borda da mata durante o dia. Estava ativa no mês de fevereiro e a atividade parece ser diurna. A dieta é composta por anuros e pequenos lagartos (Marques et al. 2004). Vestígios de anuros foram encontrados no tubo digestivo do único espécime examinado.

\section{Thamnodynastes cf. nattereri}

Espécie comum pelos métodos de amostragens utilizados, podendo ocupar a borda da mata $(\mathrm{N}=3)$ e mata $(\mathrm{N}=2)$. Foi encontrada deslocando-se no chão $(\mathrm{N}=4)$, e sobre a vegetação $(\mathrm{N}=1)$. O indivíduo encontrado sobre vegetação estava deslocando-se sobre bromélias, a cerca de 1,5 m do chão, durante a noite. Foi mais abundante nos meses mais quentes, de outubro a março $(\mathrm{N}=4)$. A atividade desta espécie parece ser crepuscular e noturna (Marques \& Sazima 2004), no entanto, pode ser encontrada ativa durante o dia, do meio para o final da tarde $(\mathrm{N}=4)$. A dieta parece ser composta principalmente de anuros (Strüssmann 1992, Rocha \& Vrcibradic 1998, Bernarde et al. 2000a, Marques $\&$ Sazima 2004). Nenhuma presa foi encontrada no tubo digestivo dos indivíduos examinados.

\section{Thamnodynastes strigatus}

Espécie rara pelos métodos de amostragens utilizados, foi encontrada em área de campo, próxima a charco. Espécie semiarborícola, utiliza a vegetação para forragear e repousar, principalmente à noite (Bernarde et al. 2000a). O único indivíduo foi encontrado no mês de abril, durante o dia. A atividade é principalmente noturna, mas também foi encontrada ativa durante o dia em outro estudo (Bernarde et al. 2000a). A dieta é composta principalmente por anuros, mas pode apresar outros tipos de presas como pequenos mamíferos e lagartos (Marques et al. 2004). Foi encontrado um anuro (Leptodactylus sp.) no tubo digestivo do indivíduo examinado. Thamnodynastes strigatus forrageia ativamente em diferentes substratos (Bernarde et al. 2000b), escolhendo-os possivelmente em função da disponibilidade de presas.

\section{Tropidodryas striaticeps}

Espécie rara pelos métodos de amostragens utilizados e de hábito semi-arborícola, foi encontrada no chão, atravessando uma estrada entre áreas de mata, às 10:00h da manhã. O único indivíduo encontrado estava ativo no mês de novembro. A atividade parece ser diurna (Thomas \& Dixon 1977). A dieta é generalista e caracterizada por mudança ontogenética. Os juvenis alimentam-se de lagartos e anuros, passando a apresar roedores e aves quando adultos (Thomas \& Dixon 1977, Sazima \& Puorto 1993). O indivíduo capturado não apresentava alimento no tubo digestivo. Para caçar, pode ficar de espreita e usar engodo caudal para atrair suas presas (Sazima \& Puorto 1993). Além desta estratégia, é provável que as espécies de Tropidodryas também forrageiem ativamente, pelo chão ou na vegetação (Sazima \& Puorto 1993).

\section{Uromacerina ricardinii}

Espécie rara pelos métodos de amostragens utilizados, sendo que somente um indivíduo foi encontrado. Uma fêmea grávida foi encontrada no Núcleo Santa Virgínia, na borda da mata, deslocandose pelo chão. A fêmea $(\mathrm{CRC}=937 \mathrm{~mm}$.) foi mantida em cativeiro e no dia 12 de novembro de 2003 fez postura de cinco ovos e no final de janeiro de 2004 quatro filhotes eclodiram (Hartmann 2006). Situação semelhante foi observada por Morato \& Bérnils (1989), com desova em novembro e eclosão em fevereiro. Marques (1998) encontrou ovos no oviduto de uma fêmea coletada em novembro e folículos vitelogênicos ( $>5 \mathrm{~mm}$ ) em agosto. Uma fêmea encontrada em Ubatuba apresentava folículos com $5 \mathrm{~mm}$ (obs. pess). As informações disponíveis indicam que $U$. ricardinii tem reprodução sazonal, com postura dos ovos nos mês de novembro e dezembro e eclosão dos filhotes entre fevereiro e março. A atividade parece ser diurna e a dieta é composta principalmente por anuros. Os filhotes mantidos em cativeiro consumiram indivíduos recém metamorfoseados de Thoropa taophora. Os anuros foram colocados no terrário no lado oposto ao da serpente. As presas foram percebidas pela serpente por meio do movimento. A serpente começava a dardejar a língua, movendo-se lentamente sobre os galhos em que estava apoiada, em direção ao anuro. Quando próxima o suficiente, deslocava-se rapidamente e abocanhava a presa, erguendo-a do solo. Com a presa erguida, começava a mover as mandíbulas para frente, puxando o anuro para dentro da boca. A ingestão começava pela extremidade mais próxima da mordida. Com a presa parcialmente ingerida, erguia a parte anterior do corpo e colocava a presa acima da cabeça, o que facilitava a ingestão. A ingestão ocorria com o anuro ainda vivo. Após a ingestão deslocava-se para um galho e permanecia estendida e imóvel.

\section{Xenodon neuwiedii}

Espécie comum pelos métodos de amostragens utilizados. Foi encontrada em áreas abertas $(\mathrm{N}=8)$, borda de mata $(\mathrm{N}=8)$ e mata $(N=7)$. Foi mais abundante no final da estação quente, entre fevereiro e maio $(\mathrm{N}=18)$. A atividade é diurna, como indicam os indivíduos encontrados em atividade e durante o dia $(\mathrm{N}=21)$. Dois machos e uma fêmea foram encontrados juntos no chão da mata em possível comportamento de corte. A fêmea tinha ovos no oviduto $(\mathrm{N}=14$, tamanho do maior ovo $=28$ $\mathrm{mm}$ ). Esta espécie tem reprodução contínua ao longo do ano (Jordão 1996, Marques 1998). A dieta é composta por anuros, principalmente do gênero Rhinella (Sazima \& Haddad 1992, Jordão 1996, Marques \& Sazima 2004). No entanto, no tubo digestivo de indivíduos examinados foram encontrados anuros de três famílias (Bufonidae, Hylidae e Leptodactylidae) e um lagarto (Enyalius sp.), todos ingeridos pela cabeça $(\mathrm{N}=7)$. Marques \& Sazima (2004) encontraram como item alimentar de $X$. neuwiedii, além de bufonídeos, um leptodactilídeo e um hilídeo. Indivíduos foram observados enquanto deslocavamse lentamente pelo chão da mata, esquadrinhando o ambiente $(\mathrm{N}=3)$. Um indivíduo foi observado na borda de um charco dentro da mata, deslocando-se entre tufos de vegetação, e outro acabando de ingerir um anuro (Proceratophrys sp.), na beira de trilha de mata, em dia chuvoso. Dois indivíduos foram observados deslocando-se na borda da mata em dia chuvoso. Xenodon neuwiedii forrageia ativamente no chão da mata e arredores, investigando o substrato. Estas informações indicam que esta espécie tem comportamento alimentar oportunista, 
podendo capturar diferentes tipos de presas, que encontra em atividade ou repousando, principalmente no chão da mata.

\section{FAMÍLIA ELAPIDAE}

\section{Micrurus corallinus}

Espécie rara pelos métodos de amostragens utilizados, foi encontrada em área aberta $(\mathrm{N}=1)$. O hábito é terrícola e criptozóico e o uso do ambiente subterrâneo parece associado à procura de alimento ou repouso (Marques 1992). O único registro foi em fevereiro. A dieta é composta por vertebrados alongados (Marques \& Sazima 1997).

\section{Micrurus decoratus}

Espécie de abundância intermediária pelos métodos de amostragens utilizados, ocorreu em área de mata preservada $(\mathrm{N}=2)$. De hábito terrícola e criptozóico, foi encontrada deslocando-se pelo chão $(\mathrm{N}=2)$. Os encontros ocorreram em janeiro e março. A atividade pode ser diurna e noturna (Marques et al. 2004) e os dois indivíduos encontrados no Núcleo Santa Virgínia estavam ativos durante o dia. A dieta é composta por giminofionas e anfisbenas (Marques 2002). Aparentemente procura suas presas ativamente, na serapilheira ou em seus abrigos sob o solo.

\section{FAMÍLIA VIPERIDAE}

\section{Bothrops jararaca}

Espécie comum pelos métodos de amostragens utilizados, foi encontrada principalmente na borda da mata $(\mathrm{N}=27)$, mas também dentro da mata $(\mathrm{N}=4)$ e em área aberta $(\mathrm{N}=3)$. Um macho adulto foi encontrado sobre a vegetação dentro da mata, a cerca de $1 \mathrm{~m}$ de altura, repousando enrodilhado. Foi encontrada na maior parte do ano, com exceção dos meses de julho e agosto. No entanto, apresentou picos de atividade na época quente e chuvosa, de outubro a março $(\mathrm{N}=25)$ semelhante ao relatado por Sazima $(1989,1992)$. Foram encontrados indivíduos ativos durante o dia $(\mathrm{N}=22)$, em espreita na borda ou dentro da mata ou deslocando-se próximo a charco. Um exemplar foi encontrado forrageando ativamente no crepúsculo e outro em postura de espreita durante a noite. Fêmeas grávidas foram encontradas assoalhando enrodilhadas na borda da mata, durante o dia $(\mathrm{N}=9)$. Indivíduos repousando foram encontrados sob monte de lenha $(\mathrm{N}=1)$, dentro de buraco em barranco na borda da mata $(\mathrm{N}=1)$, em galpão $(\mathrm{N}=1)$ e sobre a vegetação $(\mathrm{N}=1)$. A dieta é composta principalmente de anuros nos filhotes e pequenos mamíferos nos adultos (Sazima 1992, Hartmann et al. 2003, Marques \& Sazima 2004). Encontramos roedores ( $\mathrm{N}=4$ ) e vestígios de mamíferos (pêlos; $\mathrm{N}=6$ ). Em um filhote foi encontrado um lagarto (Placosoma sp.).

\section{Bothrops jararacussu}

Espécie rara pelos métodos de amostragens utilizados, somente um indivíduo foi encontrado atropelado entre áreas de mata, no mês de dezembro. Apresenta variação ontogenética na dieta, com filhotes apresando principalmente anuros e os adultos consumindo mamíferos (Martins et al., 2001).

\section{Crotalus durissus}

Espécie comum pelos métodos de amostragens utilizados, pode ocupar borda de mata $(\mathrm{N}=6)$ e área aberta $(\mathrm{N}=2)$. O hábito é terrícola (Salomão et al. 1995, Sazima \& Haddad 1992), sendo que todos os indivíduos foram encontrados no chão $(\mathrm{N}=8)$. Espécie típica de áreas abertas (Amaral 1978, Bastos et al. 2005), três indivíduos foram encontrados em área cercada por mata preservada. Foi mais encontrada nos meses de março a abril $(\mathrm{N}=6)$. A atividade é crepuscular e noturna $(\mathrm{N}=3$, Sazima \& Haddad 1992), embora possa ser encontrada ativa durante o dia
$(\mathrm{N}=5)$. Alimenta-se de pequenos mamíferos, principalmente roedores (Salomão et al. 1995, Sant'Ana 1999). Nos indivíduos examinados foram encontrados vestígios de mamíferos (pêlos; $\mathrm{N}=2$ ) e roedores ( $\mathrm{N}=2$; consumidos pelo mesmo indivíduo).

\section{Ecologia da taxocenose}

\subsection{Atividade sazonal}

A atividade das serpentes mostrou diferença significativa entre a estação chuvosa (mais quente) e a estação seca (ou menos chuvosa e mais fria; $\chi^{2}=4,27$, g.l. $=1, p=0,03$ ). Serpentes ativas (i. e., não repousando), de ambos os sexos, foram encontradas principalmente no início e no fim da estação chuvosa (Figura 2). A quantidade de serpentes encontradas caiu nos meses mais frios do ano, de junho a agosto. Quando consideradas somente as serpentes adultas, também houve diferença significativa entre as estações $\left(\chi^{2}=3,89\right.$, g.1. $=1$, $\mathrm{p}=0,04)$. As variáveis que aparentemente mais tiveram efeito sobre a abundância de serpentes adultas foram a temperatura mínima (Regressão Múltipla, $\mathrm{Rp}=798 ; \mathrm{p}=0,001 ; \mathrm{N}=123$ ) e a temperatura média (Regressão Múltipla, $\mathrm{Rp}=735 ; \mathrm{p}=0,006 ; \mathrm{N}=123$ ). A pluviosidade e a temperatura máxima aparentemente também tem algum efeito, porém de forma menos pronunciada (Regressão Múltipla, $\mathrm{Rp}=618$; $\mathrm{p}=0,032 ; \mathrm{N}=123$, para pluviosidade $\mathrm{Rp}=594 ; \mathrm{p}=0,041 ; \mathrm{N}=123$, para a temperatura máxima).

O padrão de atividade sazonal das serpentes pode ser influenciado por fatores abióticos como temperatura e pluviosidade (Gibbons \& Semlitsch 1987). Principalmente as temperaturas baixas parecem ser um fator limitante para atividade da maioria das serpentes (Gibbons \& Semlitsch 1987, Sawaya et al. 2008), pois
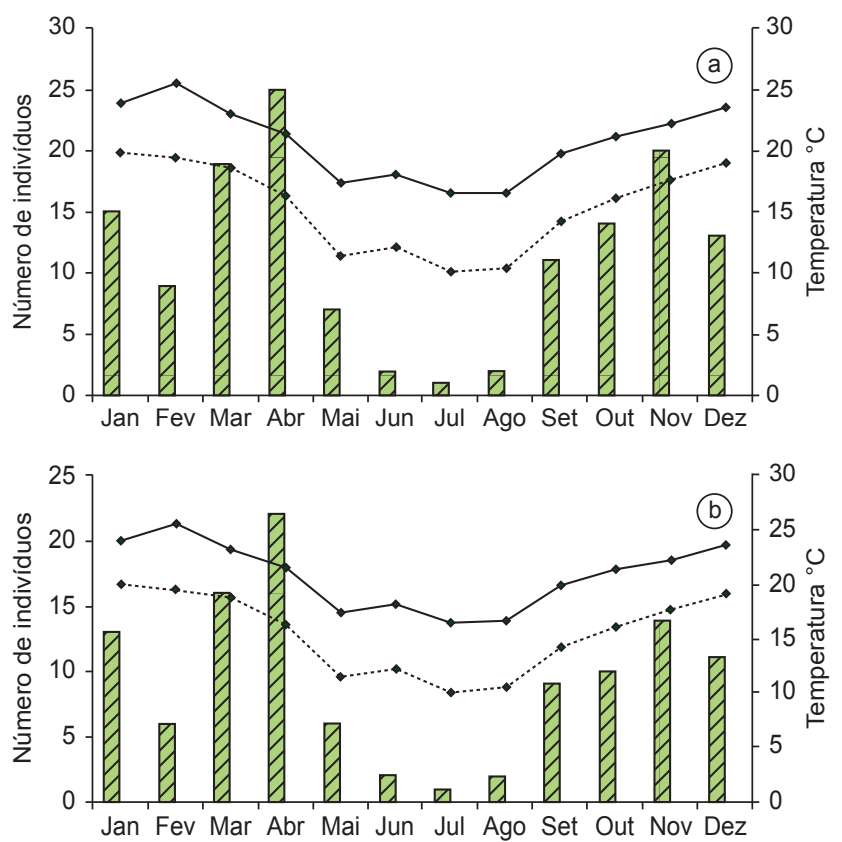

Figura 2. Número total de serpentes (A, barras, $N=137$ ) e de serpentes adultas ( $\mathrm{B}$, barras, $\mathrm{N}=123$ ), e temperatura mínima e média (linhas), de janeiro a dezembro de 2003, no Núcleo Santa Virgínia do Parque Estadual da Serra do Mar.

Figure 2. Total number of snakes (A, bars, $\mathrm{N}=212$ ) and of adult snakes (B, bars, $\mathrm{N}=105)$, and minimum and mean monthly temperatures $\left({ }^{\circ} \mathrm{C}\right.$; lines) from January to December 2003 at Núcleo Santa Virgínia, Parque Estadual da Serra do Mar. 
podem reduzir as taxas metabólicas das serpentes limitando sua atividade (Lillywhite 1987). No Núcleo Santa Virgínia, a variação sazonal de temperatura é claramente percebida, com temperaturas sensivelmente mais baixas de maio a setembro. Fatores bióticos como disponibilidade de presas e época reprodutiva também podem ser responsáveis por diferenças na taxa de encontro de serpentes ao longo do ano (Marques 1998, Marques et al. 2000). Espécies de serpentes batracófagas (Chironius spp. e Echinanthera spp.) foram encontradas somente na estação chuvosa, ou seja, foram mais ativas na época de maior disponibilidade de alimento. Entretanto, a coincidência de atividade entre serpentes batracófagas e suas presas pode refletir respostas de ambos os grupos a um mesmo fator ambiental ou conjunto de fatores ambientais (e. g., temperatura e/ou pluviosidade; Oliveira \& Martins, 2002). Na área de estudo é possível que os dois fatores estejam atuando conjuntamente: queda na atividade imposta pelas baixas temperaturas no inverno e aumento da atividade no verão, incluindo atividade reprodutiva, proporcionado pelas temperaturas mais altas e, nos casos das espécies batracófagas, pela maior disponibilidade de presas.

\subsection{Atividade diária e uso do substrato}

Na taxocenose de serpentes do Núcleo Santa Virgínia, 14 espécies são predominantemente diurnas (52\%), sendo que quatro podem estender sua atividade até o crepúsculo vespertino (Tabela 2). As espécies de Chironius, além de Tropidodryas striaticeps e Micrurus corallinus, podem permanecer ativas ao final da tarde e início da noite. Seis espécies são ativas exclusivamente durante a noite (22\%) e sete espécies podem ser encontradas ativas nos dois períodos (26\%). A condição mais frequente de uso do substrato é o hábito terrícola (17 espécies, 63\%), sendo que Micrurus spp. podem ser consideradas parcialmente fossórias e Liophis miliaris parcialmente aquática. Seis espécies foram consideradas semi-arborícolas (22\%) e três predominantemente arborícolas (11\%). Uma espécie é fossória e/ou criptozóica (Atractus sp., Tabela 2).

\subsection{Dieta}

A maioria das espécies encontradas na taxocenose apresenta dieta concentrada em uma categoria de presa ou restrita a poucos tipos de itens alimentares (dieta especializada). Algumas espécies podem capturar mais de um tipo de presas, mas o fazem apenas eventualmente. Poucas espécies consomem diferentes categorias de itens alimentares e podem ser consideradas generalistas. O item alimentar mais freqüente na dieta da taxocenose foi anuros (50\% dos itens alimentares identificados, Tabela 3). Quatorze espécies podem consumir anuros (52\%) e 12 tem anuros como item principal da dieta. Doze espécies podem se alimentar de lagartos (44\%) e pelo menos uma espécie (Siphlophis pulcher) tem lagartos como item principal da dieta. Além desta, Mussurana montana e Oxyrhopus clathratus podem capturar freqüentemente estas presas. Cerca de $10 \%$ dos itens alimentares identificados foram lagartos. Nove espécies de serpentes podem consumir mamíferos (33\%). Destas, quatro têm mamíferos como item principal da dieta. Além dos adultos de Bothrops spp., outro viperídeo, Crotalus durissus, tem como item alimentar principal pequenos mamíferos (principalmente roedores). Mamíferos foram o segundo item mais freqüentemente encontrado no tubo digestivo das serpentes (27\% dos itens alimentares identificados). Quatro espécies alimentam-se de vertebrados alongados (15\%). Além de Micrurus corallinus, também podem consumir freqüentemente outras serpentes Liophis aesculapii e Mussurana montana. Elapomorphus quinquelineatus captura principalmente anfisbenas e gimnofionas. Duas espécies consomem moluscos (7\%) e uma (Atractus sp.) consome invertebrados subterrâneos, principalmente minhocas. Aparentemente, somente Liophis miliaris consome peixes. Duas
Tabela 2. Atividade diária e uso do substrato das serpentes encontradas no Núcleo Santa Virgínia do Parque Estadual da Serra do Mar, de janeiro de 2003 a março de 2004. Indivíduos encontrados ativos (A), em repouso (R), durante o dia (D) e durante a noite (N), em cada substrato.

Table 2. Daily activity and substrate use for each species recorded at Núcleo Santa Virgínia, Parque Estadual da Serra do Mar, from January 2003 to March 2004. Snakes found active (A), resting (R), during day (D) and at night (N), in each substrate.

\begin{tabular}{|c|c|c|c|}
\hline Família/espécie & Chão & Vegetação & $\begin{array}{l}\text { Corpos } \\
\text { d'água }\end{array}$ \\
\hline \multicolumn{4}{|l|}{ COLUBRIDAE } \\
\hline Chironius bicarinatus & $3 \mathrm{AD}$ & $2 \mathrm{AD}$ & - \\
\hline Chironius exoletus & $1 \mathrm{AD}$ & $1 \mathrm{AD}$ & - \\
\hline \multicolumn{4}{|l|}{ DIPSADIDADE } \\
\hline Atractus sp. & $3 \mathrm{AD}$ & - & - \\
\hline Dipsas alternans & - & $1 \mathrm{AN}$ & - \\
\hline Echinanthera melanostigma & $5 \mathrm{AD}$ & - & - \\
\hline Echinanthera undulata & $5 \mathrm{AD}$ & - & - \\
\hline Elapomorphus quinquelineatus & $1 \mathrm{AN}$ & - & - \\
\hline Liophis aesculapii & $5 \mathrm{AD}$ & - & - \\
\hline Liophis atraventer & $9 \mathrm{AD}$ & - & - \\
\hline Liophis miliaris & - & - & $1 \mathrm{AN}$ \\
\hline Mussurana montana & 2 & - & - \\
\hline Oxyrhopus clathratus & $1 \mathrm{AD}, 1 \mathrm{AN}$ & - & - \\
\hline Philodryas patagoniensis & $3 \mathrm{AD}$ & - & - \\
\hline Sibynomorphus neuwiedi & $1 \mathrm{RD}$ & - & - \\
\hline Siphlophis pulcher & $1 \mathrm{D}$ & - & - \\
\hline Taeniophallus affinis & $4 \mathrm{AD}$ & - & - \\
\hline Taeniophallus persimilis & - & - & - \\
\hline Thamnodynastes cf. nattereri & $4 \mathrm{AD}$ & $1 \mathrm{AN}$ & - \\
\hline Thamnodynastes strigatus & - & - & $1 \mathrm{AD}$ \\
\hline Tropidodryas striaticeps & $1 \mathrm{AD}$ & - & - \\
\hline Uromacerina ricardinii & $1 \mathrm{AD}$ & - & - \\
\hline Xenodon neuwiedii & $21 \mathrm{AD}$ & - & - \\
\hline \multicolumn{4}{|l|}{ ELAPIDAE } \\
\hline Micrurus corallinus & $1 \mathrm{D}$ & - & - \\
\hline Micrurus decoratus & $2 \mathrm{AD}$ & - & - \\
\hline VIPERIDAE & - & - & - \\
\hline Bothrops jararaca & $\begin{array}{c}24 \mathrm{AD}, \\
7 \mathrm{RD}\end{array}$ & $1 \mathrm{RD}$ & - \\
\hline Bothrops jararacussu & $1 \mathrm{D}$ & - & - \\
\hline Crotalus durissus & $\begin{array}{c}6 \mathrm{AD}, \\
1 \mathrm{RD}, 2 \mathrm{AN}\end{array}$ & - & - \\
\hline
\end{tabular}

(7\%) espécies podem consumir aves, mas nenhuma parece fazê-lo com frequiência.

A grande proporção de serpentes que se alimentam de anuros evidencia a importância deste tipo de presa como recurso alimentar nas espécies de serpentes da taxocenose. Anuros são presas comuns na dieta das serpentes na Mata Atlântica e ambientes associados (Marques 1998, Di-Bernardo, 1998, Argôlo 2004, Outeiral 2006, Zanella \& Cechin 2006, Balestrin 2008), possivelmente por sua abundância e grande capacidade de ocupação de diferentes habitats. No Núcleo Santa Virgínia a diversidade estimada de anuros é de 50 espécies (Giasson 2008) e em muitos ambientes 
Tabela 3. Dieta, período de atividade e uso do substrato das serpentes encontradas de janeiro de 2003 a março de 2004 no Núcleo Santa Virgínia do Parque Estadual da Serra do Mar. Entre parênteses estão representadas observações esporádicas. An = anuros, Af = anfisbenas, Av = aves, $\mathrm{Gi}=$ gimnofionas, $\mathrm{La}=$ lagartos, $\mathrm{Mi}=$ minhocas, $\mathrm{Ma}=$ mamíferos, $\mathrm{Mo}=$ moluscos, $\mathrm{Pe}=$ peixes, $\mathrm{Se}=$ serpentes $; \mathrm{D}=$ diurna, $\mathrm{N}=$ noturna, $\mathrm{C}=$ crepuscular, $\mathrm{Sa}=$ semi-arborícola, $\mathrm{Ar}=$ arborícola, $\mathrm{Aq}=$ aquática, $\mathrm{Fo}=$ fossórea, $\mathrm{Te}=$ terrícola.

Table 3. Diet, daily activity and substrate use for each species recorded at Núcleo Santa Virgínia, Parque Estadual da Serra do Mar, from January 2003 to March 2004. Between parenthesis are the sporadic observations. An = anurans, Af = amphisbaenians, $\mathrm{Av}=$ birds, $\mathrm{Gi}=$ caecilians, $\mathrm{La}=$ lizards, $\mathrm{Mi}=$ earthworm, $\mathrm{Ma}=$ mammals, $\mathrm{Mo}=$ molluscs, $\mathrm{Pe}=$ fish, $\mathrm{Se}=$ snakes; $\mathrm{D}=$ diurnal, $\mathrm{N}=$ nocturnal, $\mathrm{C}=$ crepuscular, $\mathrm{Sa}=$ semi-arborial $, \mathrm{Ar}=\operatorname{arborial}, \mathrm{Aq}=\mathrm{aquatic}$, $\mathrm{Fo}=$ fossorial, $\mathrm{Te}=$ terrestrial .

\begin{tabular}{|c|c|c|c|}
\hline Família/espécie & Dieta & Período de atividade & Uso do substrato \\
\hline \multicolumn{4}{|l|}{ COLUBRIDAE } \\
\hline Chironius bicarinatus & $\mathrm{An}(\mathrm{La}, \mathrm{Av})$ & $\mathrm{D}(\mathrm{C})$ & $\mathrm{Sa}$ \\
\hline Chironius exoletus & An & $\mathrm{D}(\mathrm{C})$ & $\mathrm{Sa}$ \\
\hline \multicolumn{4}{|l|}{ DIPSADIDADE } \\
\hline Atractus sp. & $\mathrm{Mi}$ & ND & Fo, Te \\
\hline Dipsas alternans & Mo & $\mathrm{N}$ & $\mathrm{Ar}$ \\
\hline Echinanthera melanostigma & An & $\mathrm{D}$ & $\mathrm{Te}$ \\
\hline Echinanthera undulata & An & $\mathrm{D}$ & $\mathrm{Te}$ \\
\hline Elapomorphus quinquelineatus & Af, Gi & $\mathrm{N}$ & $\mathrm{Te}$ \\
\hline Liophis aesculapii & $\mathrm{Se}$ & $\mathrm{D}$ & $\mathrm{Te}$ \\
\hline Liophis atraventer & An & $\mathrm{D}$ & $\mathrm{Te}$ \\
\hline Liophis miliaris & An, (Pe, La, Ma, ovo An) & $\mathrm{DN}$ & Aq, Te \\
\hline Mussurana montana & $\mathrm{Se}, \mathrm{La}$ & $\mathrm{N}$ & $\mathrm{Te}$ \\
\hline Oxyrhopus clathratus & $\mathrm{Ma}, \mathrm{La}$ & ND & $\mathrm{Te}$ \\
\hline Philodryas patagoniensis & An, (Ma, La, Av) & $\mathrm{D}$ & $\mathrm{Te}$ \\
\hline Sibynomorphus neuwiedi & Mo & $\mathrm{N}$ & $\mathrm{Ar}$ \\
\hline Siphlophis pulcher & $\mathrm{La}, \mathrm{Se}$ & $\mathrm{N}$ & $\mathrm{Sa}$ \\
\hline Taeniophallus affinis & An (La) & $\mathrm{D}$ & $\mathrm{Te}$ \\
\hline Taeniophallus persimilis & An & $\mathrm{D}$ & $\mathrm{Te}$ \\
\hline Thamnodynastes cf. nattereri & An, (Ma, La) & $\mathrm{DN}$ & $\mathrm{Sa}$ \\
\hline Thamnodynastes strigatus & An, (Ma, La) & $\mathrm{DN}$ & $\mathrm{Sa}$ \\
\hline Tropidodryas striaticeps & $\mathrm{La}, \mathrm{An}, \mathrm{Ma}, \mathrm{Av}$ & DC & $\mathrm{Sa}$ \\
\hline Uromacerina ricardinii & An, (La) & $\mathrm{D}$ & $\mathrm{Ar}$ \\
\hline Xenodon neuwiedii & An, (La) & $\mathrm{D}$ & $\mathrm{Te}$ \\
\hline \multicolumn{4}{|l|}{ ELAPIDAE } \\
\hline Micrurus corallinus & Af, Gi (Se) & $\mathrm{D}(\mathrm{c})$ & Te, Fo \\
\hline Micrurus decoratus & Af, Gi & $\mathrm{D}$ & Te, Fo \\
\hline \multicolumn{4}{|l|}{ VIPERIDAE } \\
\hline Bothrops jararaca & $\mathrm{Ma}(\mathrm{An}, \mathrm{La})$ & $\mathrm{DN}$ & $\mathrm{Te}$ \\
\hline Bothrops jararacussu & $\mathrm{Ma}(\mathrm{An}, \mathrm{La})$ & $\mathrm{DN}$ & $\mathrm{Te}$ \\
\hline Crotalus durissus & Ma & $\mathrm{CN}$ & $\mathrm{Te}$ \\
\hline
\end{tabular}

onde encontramos serpentes podemos associar com ambientes ocupados por anuros.

\subsection{Estrutura da taxocenose}

De acordo com a caracterização dos itens alimentares principais, uso do substrato e período de atividade, identificamos cinco grupos de espécies com semelhanças ecológicas (ou guildas; ver Tabela 3). Espécies que consomem principalmente anuros, de atividade diurna e/ou crepuscular e semi-arborícolas: Chironius bicarinatus, C. exoletus, Thamnodynastes $\mathrm{cf}$. nattereri e T. strigatus. Espécies que consomem principalmente anuros, de atividade diurna e terrícolas: Echinanthera melanostigma, E. undulata, Liophis atraventer, Taeniophallus affinis, T. persimilis e Xenodon neuwiedii. Espécies que consomem principalmente mamíferos, de atividade noturna e terrícolas: Bothrops jararaca, Bothrops jararacussu, Crotalus durissus e Oxyrhopus clathratus. Espécies que consomem principalmente vertebrados alongados, de atividade diurna e terrícolas e/ou fossóreas: Liophis aesculapii, Micrurus corallinus e M. decoratus.

Estas semelhanças ecológicas mostram sobreposição no uso dos recursos entre alguns grupos de espécies na taxocenose de serpentes do Núcleo Santa Virgínia. Pequenas diferenças, principalmente na freqüência de consumo dos itens alimentares ou uso do substrato, podem ser percebidas (ver História natural das espécies). Estas diferenças são esperadas, pois é extremamente improvável que duas espécies, mesmo que sejam irmãs, permaneçam idênticas em sua ecologia após os milhões de anos decorridos desde que as mesmas derivaram de um ancestral comum. Entretanto, essas diferenças poderiam ser atribuídas à competição passada por determinados recursos 
(e. g., Henderson et al. 1979), embora muitas vezes diferenças na frequiência de uso de recurso entre populações da mesma espécie são maiores do que diferenças interespecíficas, o que indica que esta variação pode não estar relacionada à presença de outra espécie (Connell 1980). Por outro lado, para existir competição, os recursos necessariamente devem ser limitados. Estudos com taxocenoses neotropicais nos quais a abundância de serpentes e de suas presas foi monitorada, mesmo que de forma não sistematizada (e. g., Martins \& Oliveira 1999, Sawaya et al. 2008), indicam que a abundância de presas não é limitada o suficiente para se tornar um agente seletivo importante na diferenciação entre espécies.

A composição das taxocenoses neotropicais parece refletir as probabilidades de colonização da área por diferentes linhagens. Por exemplo, há uma mudança na contribuição das diferentes linhagens de colubrídeos neotropicais quando se examina estas taxocenoses no sentido norte-sul (Cadle \& Greene 1993). Esta mudança na composição faunística interfere nos padrões de utilização de recursos, pois estes parecem refletir as tendências e limitações inerentes a cada uma das linhagens que compõem a taxocenose (Cadle \& Greene 1993). A taxocenose de serpentes do Núcleo Santa Virgínia mostra um predomínio de espécies terrícolas e/ou semi-arborícolas, diurnas e batracófagas, padrões amplamente difundidos na linhagem Xenodontinae (Dipsadidade). É importante ressaltar, no entanto, que são necessárias mais informações, principalmente de história natural das espécies, para que se possa ter uma visão mais nítida de quais os fatores que influenciam mais fortemente as estruturas das taxocenoses nos diferentes ambientes.

\section{Agradecimentos}

Ao Instituto Florestal de São Paulo, especialmente a João Paulo Villani, administrador do Núcleo Santa Virgínia do Parque Estadual da Serra do Mar, pela permissão de acesso e apoio logístico. Ao Instituto Brasileiro do Meio Ambiente e dos Recursos Naturais Renováveis (IBAMA), pela autorização de captura e coleta (02027.010399/01-46). Agradecemos também ao Instituto Butantan, especialmente a Francisco Franco, Maria de Fátima Furtado, Myriam Calleffo, Otávio Marques e Valdir Germano pela permissão para examinar espécimes tombados na coleção e ajuda nos trabalhos de laboratório. Contribuíram de forma valorosa nos trabalhos de campo André Antunes, Guilherme Guidolim, Marcos Geraldes e Luis O. M. Giasson. Ivan Sazima, Otávio A. V. Marques, Célio Haddad and Luis O. M. Giasson fizeram sugestões importantes durante o trabalho de campo e na elaboração do manuscrito. P. A. Hartmann agradece ao Conselho de Aperfeiçoamento de Pessoal de Nível Superior (CAPES) pela bolsa de Doutorado. O trabalho de campo foi financiado em grande parte pela Fundação de Amparo à Pesquisa do Estado de São Paulo (FAPESP). Auxílio financeiro adicional foi fornecido pelo Programa de Pós-Graduação em Ciência Biológicas - Zoologia, Instituto de Biociências, Universidade Estadual Paulista, (UNESP), Rio Claro.

\section{Referências Bibliográficas}

AMARAL, A. 1978. Serpentes do Brasil: iconografia colorida. 2 ed. Melhoramentos, São Paulo.

ARGÔLO, A.J.S. 2004. Serpentes dos cacauais do sudeste da Bahia. Editus, Ilhéus.

BALESTRIN, R.L. 2008. História natural de uma taxocenose de squamata e redescoberta de uma espécie de anuro no Escudo Sul-Riograndense, Brasil. Tese de Doutorado, Pontifícia Universidade Católica do Rio Grande do Sul, Porto Alegre.

BARBO, F.E. \& MARQUES, O.A.V. 2003. Do aglyphous colubrid snakes prey on live amphisbaenids able to bite? Phyllomedusa. 2(2):113-114.
BASTOS, E.G.M., ARAUJO, A.F.B. \& SILVA, H.R. 2005. Records of the rattlesnakes Crotalus durissus terrificus (Laurenti) (Serpentes, Viperidae) in the State of Rio de Janeiro, Brazil: a possible case of invasion facilitated by deforestation. Rev. Bras. Zool. 22(3):812-815.

BERNARDE, P.S. 2004. Composição faunística, ecologia e história natural de serpentes em uma região no sudoeste da Amazônia, Rondônia, Brasil. Tese de Doutorado, Universidade Estadual Paulista, Rio Claro.

BERNARDE, P.S., KOKUBUM, M.N.C. \& MARQUES, O.A.V. 2000a. Utilização de habitat e atividade em_Thamnodynastes strigatus (GÜNTHER, 1858) no sul do Brasil (SERPENTES, COLUBRIDAE). Bol. Mus. Nac. 428:1-8.

BERNARDE, P.S., MOURA-LEITE, J.C., MACHADO, R.A. \& KOKUBUM, M.N.C. 2000b. Diet of the colubrid snake, Thamnodynastes strigatus (Günther, 1858) from Paraná state, Brazil, with fields notes on anuram predation. Rev. Bras. Biol. 60(4):695-699.

CADLE, J.E. \& GREENE, H.W. 1993. Phylogenetic patterns, biogeography, and the ecological structure of neotropical snake assemblage. In Species diversity in ecological communities: historical and geographical perspectives (R.E. Ricklefs \& D. Schulter, eds.). University of Chicago Press, Chicago, p. 281-293.

CARDOSO, S.T., ROCHA, M.M.T. \& PUORTO, G. 2001. Elapomorphus quinquelineatus. Herp. Rev. 32(4):262-263.

CARVALHO-SILVA, S.P. \& FERNANDES, R. 1994. Chironius bicarinatus. Herp. Rev. 25(1):28.

CECHIN, S.T.Z. 1999. História natural de uma comunidade de serpentes na região da Depressão Central (Santa Maria), Rio Grande do Sul, Brasil. Tese de Doutorado, Pontifícia Universidade Católica do Rio Grande do Sul, Porto Alegre.

CHICARINO, M.S., ENDO, W. \& MARQUES, O.A.V. 1998. Atividade, ciclo reprodutivo e dieta da cobra-d'agua Liophis miliaris, na porção sul da Mata Atlântica. In Resumos do XXII Congresso Brasileiro de Zoologia. UFPE, Recife, p. 271-272.

CONNELL, J.H. 1980. Diversity and the coevolution of competitors, or the ghost of competition past. Oikos. 35:131-138.

DI-BERNARDO, M. 1998. História natural de uma comunidade de serpentes da Borda Oriental do Planalto das Araucárias, Rio Grande do Sul, Brasil. Tese de Doutorado, Universidade Estadual de Paulista, Rio Claro.

DIXON, J.R. \& SOINI, P. 1986. The reptilies of the upper Amazon Basin, Iquitos region, Peru. Milwaukee Public Museum, Milwauke.

DIXON, J.R. \& THOMAS, R.A. 1985. A new species of South America water snake (genus Liophis) from southeastern Brazil. Herpetologica. 41(3):259-262.

DIXON, J.R., WIEST, J.A. \& CEI, J.M. 1993. Revision of the tropical snake Chironius Fitzinger (Serpentes, Colubridae). Monogr. Mus. Reg. Sci. Natur. 13:1-279.

DUELLMAN, W.E. 1978. The biology of an equatorial herpetofauna in Amazonian Equador. Misc. Publ. Mus. Nat. Hist. Univ. Kansas 65: $1-352$

DUELLMAN, W.E. 1989. Tropical herpetofaunal communities: patterns of community structure in neotropical rainforests. In Vertebrates in complex tropical systems (M.L. Harmelin-Vivien \& F. Bourliere, eds.). SpringerVerlag, New York, p. 61-88. (Ecological studies, v. 69).

FERNANDES, D.S., PASSOS, P., FRANCO, F.L. \& GERMANO, V.J. 2003. Liophis atraventer. Herp. Rev. 34(4):317-320.

FRANÇA, F.G.R. \& ARAÚJO, A.F.B. 2006. The conservation status of snakes in central Brazil. South Am. J. Herpetol. 1(1):25-36.

FRANCO, F.L. \& FERREIRA, T.G. 2002. Descrição de uma nova espécie de Thamnodynastes Wagler, 1830 (Serpentes, Colubridae) do nordeste brasileiro, com comentários sobre o gênero. Phyllomedusa. 1(2):57-74.

FRANCO, F.L., FERREIRA, T.G., MARQUES, O.A.V. \& SAZIMA, I. 2003. A new species of hood-displaying Thamnodynastes (Serpentes: Colubridae) from Atlantic forest in southeast Brazil. Zootaxa. 334:1-7.

FRANCO. F.L., MARQUES, O.A.V. \& PUORTO, G. 1997. Two new species of Colubrid snakes of the genus Clelia from Brazil. J. Herpetol. 31(4):483-490. 
GIASSON, L.O.M. 2008. Atividade sazonal e uso do ambiente por anfíbios da Mata Atlântica no alto da Serra do Mar. Tese de Doutorado, Universidade Estadual de Paulista, Rio Claro.

GIBBONS, J.W. \& SEMLITSCH, R.D. 1987. Activity patterns. In Snakes: ecology and evolutionary biology (R.A. Seigel, J.T. Collins \& S.S. Novak, eds.). McGraw-Hill, New York, p. 396-421.

GONZAGA, L.A.P., CASTIGLIONI, G.D.A. \& ALVES, M.A. 1997. Philodryas patagoniensis. Herp. Rev. 28(3):154.

GREENE, H.W. 1973. The food habits and feeding behavior of the new world coral snakes. Dissertação de Mestrado, University Texas, Arlington.

GREENE, H.W. 1976. Scale overlap as a directional sign stimulus for prey ingestion by ophiophagous snakes. Zool. Tierpsychol. 41(1):113-120.1

HARTMANN, P.A. 2001. Hábito alimentar e utilização do ambiente em duas espécies simpátricas de Philodryas, no sul do Brasil. Dissertação de Mestrado, Universidade Estadual Paulista, Rio Claro.

HARTMANN, P.A. 2006. Uromacerina ricardinii. Herp. Rev. 37(1):95-96.

HARTMANN, P.A. \& MARQUES, O.A.V. 2005. Diet and habitat use of two sympatric species of Philodryas (Colubridae), in south Brazil. AmphibiaReptilia. 26:25-31.

HARTMANN, P.A., HARTMANN, M.T. \& GIASSON, L.O.M. 2003. Uso do hábitat e alimentação em juvenis de Jararaca, Bothrops jararaca (Serpentes, Viperidae), na Mata Atlântica. Phyllomedusa. 2(1):35-41.

HENDERSON, R.W., DIXON, J. \& SOINI, P. 1979. Resource partitioning in Amazonian snake communities. Milw. Public. Mus. Contr. Biol. Geol. 22(1):1-11.

HENDERSON, R.W., NOESKE-HALLIN, T.A., OTTENWALDER, J.A. \& SCHWARTZ, A. 1987. On the diet of Boa Epicrates striatus on Hispaniola, with notes on E. fordi and E. gracilis. Amphibia-Reptilia. 8(3):251-258.

JORDÃO, R.S. 1996. Estudo comparativo da alimentação e da reprodução de Waglerophis merremii e Xenodon neuwiedii (SERPENTES: COLUBRIDAE). Dissertação de Mestrado, Universidade de São Paulo, São Paulo.

LILLYWHITE, H.B. 1987. Temperature, energetics, and physiological ecology. In Snakes: ecology and evolutionary biology (R.A. Seigel, J.T. Collins \& S.S. Novak, eds.). McGraw-Hill, New York, p. 422-477.

LOPEZ, M.S. 2003. Philodryas patagoniensis. Herp. Rev. 34(1):71-72.

MACHADO, R.A., BERNARDE, P.S. \& MORATO, S.A.A. 1998. Liophis miliaris. Herp. Rev. 29(1):45.

MARQUES, O.A.V. 1992. História natural de Micrurus corallinus (Serpentes, Elapidae). Dissertação de Mestrado, Universidade de São Paulo, São Paulo.

MARQUES, O.A.V. 1996. Biologia reprodutiva da cobra-coral Erythrolamprus aesculapii, Linnaeus (Colubridae), no sudeste do Brasil. Rev. Bras. Zool. 13(3):747-753.

MARQUES, O.A.V. 1998. Composição faunística, história natural e ecologia de serpentes da mata atlântica, na região da estação ecológica JuréiaItatins, São Paulo, SP. Tese de Doutorado, Universidade de São Paulo, São Paulo.

MARQUES, O.A.V. 2002. Natural history of the coral snake Micrurus decoratus (Elapidae) from the Atlantic Forest in Southeast Brazil, with comments on possible mimicry. Amphibia-Reptilia. 22:228-232.

MARQUES, O.A.V., ETEROVIC, A. \& ENDO, W. 2000. Seasonal activity of snakes in the Atlantic forest in southeastern Brazil. Amphibia-Reptilia. 22(1):103-101.

MARQUES, O.A.V., ETEROVIC, A. \& SAZIMA, I. 2004. Snakes of the Brazilian Atlantic forest: an illustrated field guide for the Serra do Mar Range. Holos, Ribeirão Preto.

MARQUES, O.A.V. \& PUORTO, G. 1994. Dieta e comportamento alimentar de Erythrolamprus aesculapii, uma serpente ofiófaga. Rev. Bras. Biol. 54(2):253-259.

MARQUES, O.A.V. \& SAZIMA, I. 1997. Diet and feeding behavior of the coral snake, Micrurus corallinus, from the Atlantic forest of Brasil. Herpetol. Nat. Hist. 5(1):88-93.
MARQUES, O.A.V. \& SAZIMA, I. 2004. História natural dos répteis da estação ecológica Juréia-Itatins. In Estação ecológica Juréia-Itatins: ambiente físico, flora e fauna (O.A.V Marques \& W. Duleba, eds.). Holos, Ribeirão Preto, p. 257-277.

MARQUES, O.A.V. \& SOUZA, V.C. 1993. Nota sobre a atividade alimentar de Liophis miliaris no ambiente marinho (Serpentes, Colubridae). Rev. Bras. Biol. 53(4):645-648.

MARTINS, M. 1994. História Natural e Ecologia de uma taxocenose de serpentes de mata na região de Manaus, Amazônia Central, Brasil. Tese de Doutorado, Universidade Estadual de Campinas, Campinas.

MARTINS, M., ARAÚJO, M.S., SAWAYA, R.J. \& NUNES, R. 2001. Diversity and evolution of macrohabitat use, body size and morphology in a monophyletic group of Neotropical pitvipers (Bothrops). J. Zool. 254(4):529-538.

MARTINS, M.R.C. \& GORDO, M. 1993. Bothrops atrox. Herp. Rev. 24(4):151-152.

MARTINS, M. \& OLIVEIRA, M.E. 1993. The snakes of the genus Atractus Wagler (Reptilia: Squamata: Colubridae) from the Manaus region, central Amazonia, Brazil. Zool. Meded. 67:21-40.

MARTINS, M.R.C. \& OLIVEIRA, M.E. 1999. Natural history of snakes in forest of the Manaus, central Amazonia, Brazil. Herpetol. Nat. Hist. 6(2):78-150.

MASCHIO, G.F. 2008. História natural e ecologia das serpentes da Floresta Nacional de Caxiuanã, Melgaço/Portel, Pará, Brasil. Tese de Doutorado, Museu Paraense Emílio Goeldi, Pará.

MORATO, S.S.A. \& BÉRNILS, R.S. 1989. Dados sobre reprodução de Uromacerina ricardinii (Peracca, 1987) (Serpentes: Colubridae) do Estado do Paraná - Brasil. Acta Biol. Leopol. 11(2):273-278.

OLIVEIRA, J.L. 2001. Ecologia de três espécies de dormideira Sibynomorphus (Serpentes: Colubridae) na Mata Atlântica. Dissertação de Mestrado, Universidade de São Paulo, São Paulo.

OLIVEIRA, M.E. \& MARTINS, M. 2002. When and where to find a pitviper: activity patterns and habitat use of the lancehead, Bothrops atrox, in central Amazonia, Brazil. Herpetol. Nat. Hist. 8(2):101-110.

OUTEIRAL, A.B. 2006. História natural de uma comunidade de serpentes da Serra do Sudeste do Rio Grande do Sul, Brasil. Tese de Doutorado, Pontifícia Universidade Católica do Rio Grande do Sul, Porto Alegre.

PETERS, J.A. \& OREJAS-MIRANDA, B. 1970. Catalogue of the neotropical squamata. Bull. U. S. Natl. Mus. 297(2):1-347. (parte I, Snakes).

PRUDENTE, A.L.C., MOURA-LEITE, J.C. \& MORATO, S.A.A. 1998. Alimentação das espécies de Siphlophis Fitzinger (Serpentes, Colubridae, Xenodontinae, Pseudoboini). Rev. Bras. Zool. 15(2):375-383.

ROCHA, C.F.D. \& VRCIBRADIC, D. 1998. Reptiles as predators of vertebrates and as prey in a restinga habitat of southestern Brazil. Ci. Cult. 50(5):364-368.

SALOMÃO, M.G., ALMEIDA-SANTOS, S.M. \& PUORTO, G. 1995. Activity pattern of Crotalus durissus (Serpentes, Crotaline), feeding, reproduction and snakebit. Stud. Neotrop. Fauna Environm. 30(2):101-106.

SANT'ANA, S. 1999. Hábito alimentar da Cascavel, Crotalus durissus no sudeste brasileiro. Dissertação de Mestrado, Universidade Estadual Paulista, Rio Claro.

SANTOS-COSTA, M.C. 2003. História natural da comunidade de serpentes da Estação Científica Ferreira Penna, Melgaço, Pará. Tese de Doutorado, Museu Paraense Emílio Goeldi, Pará.

SAWAYA, R.J., MARQUES, O.A.V. \& MARTINS, M.R.C. 2008. Composição e história natural das serpentes de Cerrado de Itirapina, São Paulo, sudeste do Brasil. Biota Neotrop. 8(2):

http://www.biotaneotropica.org.br/v8n2/pt/abstract?article+bn01308022008 ISSN 1676-0603 (último acesso em 10/09/2008).

SAZIMA, I. 1989. Feeding behavior of the snail-eating snake Dipsas indica. J. Herpetol. 23(4):464-468.

SAZIMA, I. 1992. Natural History of Jararaca pitviper, Bothrops jararaca in southeastern Brazil. In Biology of the Pitvipers (J.A. Campbell \& E.D. Brodie Jr., eds.). Selva, Tyler. 
SAZIMA, I. \& ABE, A.S. 1991. Habits of five Brazilian snakes with coralsnake pattern, including a summary of defensive tactics. Stud. Neotrop. Fauna Environm. 26(3):159-164

SAZIMA, I. \& ARGOLO, A.J.S. 1994. Siphlophis pulcher. Herp. Rev. 25(3):126.

SAZIMA, I. \& HADDAD, C.F.B. 1992. Répteis da Serra do Japi: notas sobre história natural. In História natural da Serra do Japi: ecologia e preservação de uma área florestal no sudeste do Brasil (L.P. Morellato, ed.). FAPESP, Campinas.

SAZIMA, I. \& PUORTO, G. 1993. Feeding technique of juvenile Tropidodryas striaticeps: probable caudal luring in a colubrid snake. Copeia. 1993(1):222-226.

SHINE, R. 1977. Habits, diet, and sympatry in snakes: a study of Australia. Can. J. Zool. 55(7):1118-1128.

STRÜSSMANN, C. 1992. Serpentes do Pantanal de Poconé, Mato Grosso: composição faunística, história natural e ecologia comparada. Dissertação de Mestrado, Universidade de Campinas, Campinas.

STRÜSSMANN, C. \& SAZIMA, I. 1993. The snake assemblage of the pantanal at Poconé, western Brazil: faunal composition and ecological summary. Stud. Neotrop. Fauna Environm. 28(3):157-168.

THOMAS, R.A. \& DIXON, J.R. 1977. A new systematic arrangement for Philodryas serra (Schlegel) and Philodryas pseudoserra Amaral (Serpentes: Colubridae). Peace-Sellards Ser. Texas Mem. Mus.. 27:1-20.
VANZOLINI, P.E. 1948. Notas sobre os ofídios e lagartos de emas, no município de Pirassununga, Estado de São Paulo. Rev. Bras. Biol. 8(3):377-400.

VITT, L.J. \& VANGILDER, L.D. 1983. Ecology of a snake community in northeastern Brazil. Amphibia-Reptilia. 4(2-4):273-296.

ZAHER, H., GRAZZIOTIN, F.G., CADLE, J.E., MURPHY, R.W., MOURALEITE, J.C. \& BONATTO, S.L. 2009. Molecular phylogeny of advanced snakes (Serpentes, Caenophidia) with an emphasis on South American Xenodontines: a revised classification and description of new taxa. Pap. Av. Zool. 49(11):115-153.

ZANELA, N. \& S.Z. CECHIN. 2006. Taxocenose de serpentes no Planalto Médio do Rio Grande do Sul, Brasil. Rev. Bras. Biol. 23(1):211-217.

ZIMMERMAN, B.L. \& RODRIGUES, M.T. 1990. Frogs, snakes, and lizards of the INPA/WWF reserves near Manaus, Brazil. In Four neotropical rainforests (A.H. Gentry, ed.). Yale University Press, New Haven, p. $426-454$.
Recebido em 01/12/08 Versão Reformulada recebida em 29/07/09 Publicado em 17/09/09 